\title{
Cryptic amyloidogenic elements in mutant NEFH causing Charcot-Marie-Tooth 2 trigger aggresome formation and neuronal death
}

\author{
Arnaud Jacquier ${ }^{1,2 \dagger}{ }^{+}$, Cécile Delorme ${ }^{3 \dagger}$, Edwige Belotti $^{1}$, Raoul Juntas-Morales ${ }^{4}$, Guilhem Solé ${ }^{5}$, Odile Dubourg ${ }^{6}$, \\ Marianne Giroux ${ }^{7}$, Claude-Alain Maurage ${ }^{8}$, Valérie Castellani ${ }^{1}$, Adriana Rebelo ${ }^{9}$, Alexander Abrams ${ }^{9}$, \\ Stephan Züchner ${ }^{9}$, Tanya Stojkovic ${ }^{10^{*}+}$, Laurent Schaeffer ${ }^{1,11^{* \dagger}}$ (D) and Philippe Latour ${ }^{2 \dagger}$
}

\begin{abstract}
Neurofilament heavy chain (NEFH) gene was recently identified to cause autosomal dominant axonal Charcot-Marie-Tooth disease (CMT2cc). However, the clinical spectrum of this condition and the physio-pathological pathway remain to be delineated. We report 12 patients from two French families with axonal dominantly inherited form of CMT caused by two new mutations in the NEFH gene. A remarkable feature was the early involvement of proximal muscles of the lower limbs associated with pyramidal signs in some patients. Nerve conduction velocity studies indicated a predominantly motor axonal neuropathy. Unique deletions of two nucleotides causing frameshifts near the end of the NEFH coding sequence were identified: in family 1, c.3008_3009del (p.Lys1003Argfs*59), and in family 2 c.3043_3044del (p.Lys1015Glyfs*47). Both frameshifts lead to 40 additional amino acids translation encoding a cryptic amyloidogenic element. Consistently, we show that these mutations cause protein aggregation which are recognised by the autophagic pathway in motoneurons and triggered caspase 3 activation leading to apoptosis in neuroblastoma cells. Using electroporation of chick embryo spinal cord, we confirm that NEFH mutants form aggregates in vivo and trigger apoptosis of spinal cord neurons. Thus, our results provide a physiological explanation for the overlap between CMT and amyotrophic lateral sclerosis (ALS) clinical features in affected patients.
\end{abstract}

\section{Introduction}

Charcot-Marie-Tooth disease (CMT) refers to a heterogeneous group of chronic inherited motor and sensory disorders of the peripheral nervous system. CMT are classified according to their axonal or demyelinating feature on nerve conduction studies, and their mode of inheritance [10]. The autosomal dominant axonal forms are termed CMT2. The number of genes associated with CMT is progressively expanding, particularly since the development of next-generation sequencing. Several of these genes are expressed in both the central and peripheral nervous system, such as neurofilaments, which

\footnotetext{
* Correspondence: tanya.stojkovic@aphp.fr; laurent.schaeffer@univ-lyon1.fr ${ }^{\dagger}$ Equal contributors

${ }^{10}$ Institut de Myologie, Hôpital Pitié-Salpêtrière, 47-83 boulevard de l'Hôpital, 75013 Paris, France

${ }^{1}$ Institut NeuroMyoGène, Université Lyon1 - CNRS UMR 5310 - INSERM

U1217, Lyon, France

Full list of author information is available at the end of the article
}

have been implicated in several neurodegenerative diseases, including ALS [24]. Neurofilaments are intermediate filaments exclusively expressed in neurons in the central and peripheral nervous system. They have important cytoskeletal functions such as the regulation of axonal growth and diameter [15]. Neurofilaments are composed of three subunits defined by their molecular weight: NEFL (light), NEFM (medium), and NEFH (heavy) [23, 24], encoded by NEFL, NEFM and NEFH genes, respectively. Mutations in NEFL are known to cause both axonal and demyelinating forms of CMT and manifest with various clinical phenotypes, sometimes with additional pyramidal signs $[2,4,13,19,25]$. Mutations in the NEFH gene have been suggested to play a role in the pathogenesis of sporadic amyotrophic lateral sclerosis (ALS), but with conflicting results [28].

Recently, NEFH mutations have been identified as a rare cause of autosomal dominant CMT, with two 
families reported to date [27]. The clinical and electrophysiological phenotype in these two families was characterized by a severe, predominantly motor, axonal neuropathy, with significant walking difficulties in early adulthood. Similar to our families, the two mutations (c.3010_3011delGA and c.3017_3020dup) cause the loss of the stop codon and the translation of 40 additional amino acids which encode a cryptic amyloidogenic element (CAE) and cause protein aggregation [27].

Here, we report two French families presenting with an axonal, dominantly inherited form of CMT characterized by prominent motor deficit affecting both the distal and proximal muscles, and signs of central nervous system involvement, caused by two previously unreported mutations in the NEFH gene. We show that those new mutations cause protein aggregation, not only in neuroblastoma cells as similar mutations previously reported, but also in primary mouse motoneurons. We further show that this type of mutations also induces neuronal apoptosis, both in neuroblastoma cells and in vivo in spinal cord neurons using in ovo chick spinal cord electroporation. Our results thus provide a physiological basis to the pathogenicity of $N E F H$ mutations that interfere with neurofilament assembly via protein sequestration and cause neurotoxicity, which explains the overlapping clinical features of NEFH mutations with those of motor neuron disease.

\section{Materials and methods}

\section{Patients}

The patients were identified as part of our on-going genetic studies in CMT. Patients were all of French ascendance. Patients were recruited, enrolled and sampled according to the protocols of the institutional review board at the Pitié-Salpêtrière Hospital. Written informed consent was obtained for participation in the study. Patients displayed a clinical and electrical phenotype of axonal motor and sensory neuropathy, with no mutations in known CMT2 genes at that time. Twelve patients belonging to two different families (Fig. 1) were included in the study.

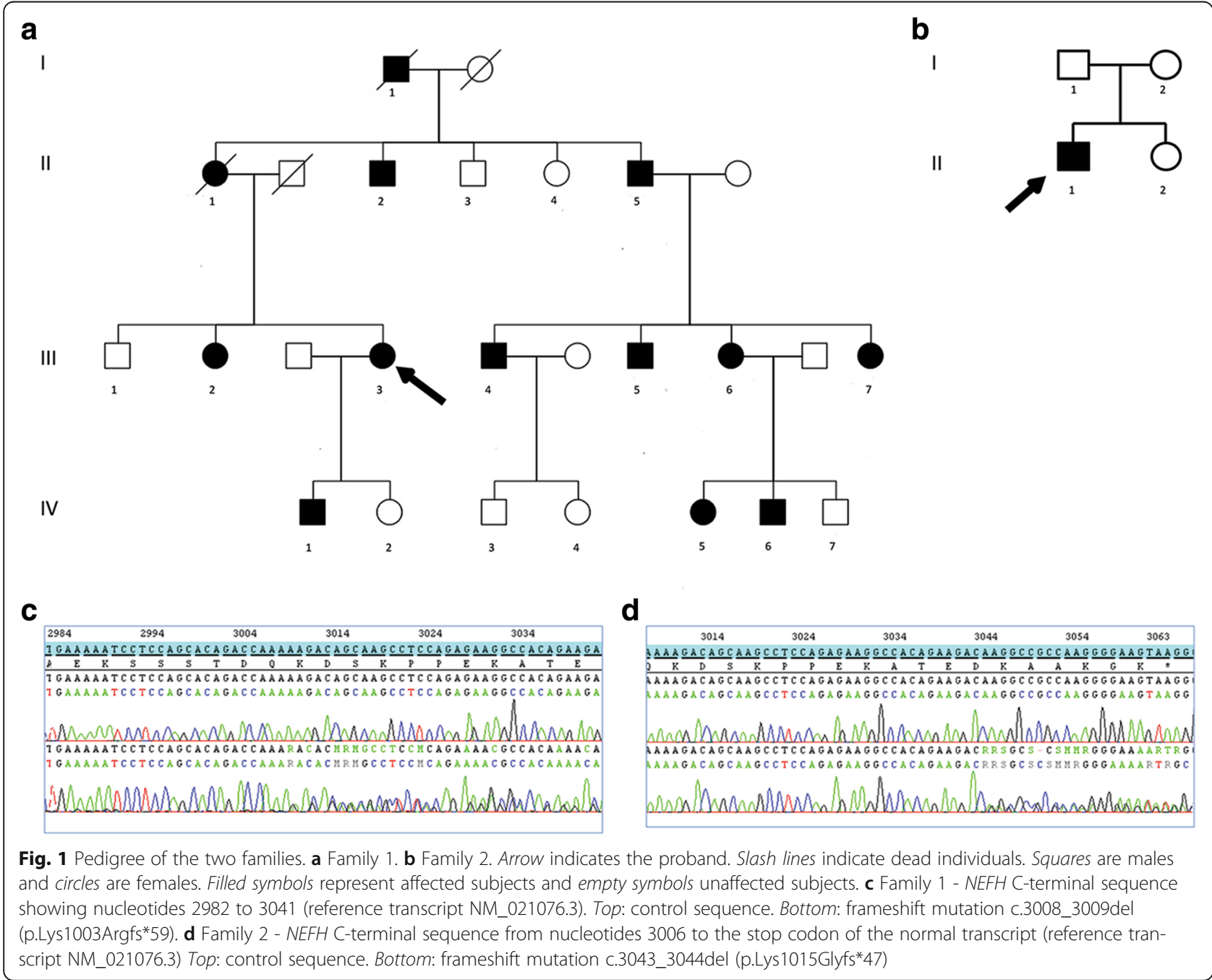




\section{Clinical assessment}

Patients were seen in neuromuscular centres and assessed by senior neurologists specialized in neuromuscular disorders in Paris (TS and OD), Lille (TS), Bordeaux (GS), Valenciennes (MG) and Montpellier (RJM). Clinical assessment included medical history and neurological examination.

\section{Neurophysiological study}

Electrodiagnostic studies included nerve conduction studies in the upper and lower limbs, and electromyography (EMG) using concentric needle electrodes in at least three muscles. Electrodiagnostic studies were performed using conventional equipment and standard methods. Skin temperature was maintained in the range of $32^{\circ}$ to $34{ }^{\circ} \mathrm{C}$. Patients were classified as having axonal neuropathy if they had a nerve conduction velocity in the median nerve above $38 \mathrm{~m} / \mathrm{s}$ [12].

\section{Histological study}

A nerve biopsy (superficial peroneal sensory nerve) was performed in patients II-1, III-4 and III-7 of family 1 . A muscle biopsy (tibialis anterior) was performed in patients III-3, III-4 and III-7 of family 1 and patient II- 1 of family 2. Muscle and nerve biopsies were processed and assessed according to standard techniques [33].

\section{Molecular analysis}

Mutations in genes frequently associated with axonal CMT (MFN2, GJB1; MPZ, TRPV4, NEFL, GDAP) and amyotrophic lateral sclerosis (ALS), such as SOD1gene, were first excluded by Sanger sequencing. In family 1, four patients were then studied by sequencing a panel of 4813 genes associated with known clinical phenotypes (Illumina ${ }^{\oplus}$ TruSight One Sequencing Panel) on Illumina ${ }^{\oplus}$ NextSeq500 sequencer. In family 2, the index case and his two parents were sequenced by the same method. Confirmation of the putative deleterious variants in $N E F H$ and familial studies were done by Sanger sequencing.

\section{Plasmid construct and mutagenesis}

The construct encoding for the human NEFH was a gift from Dr Sidransky [21] and it was subcloned in a pCAGEN eGFP C1 plasmid allowing optimal expression in neurons. NEFH N-terminus end was fused with monomeric eGFP (derived from peGFP-C1, clonetech) using Gibson assembly kit (E5510, NEB) following the manufacturer recommendation to obtain pCAGEN eGFP NEFH referred to as WT NEFH thereafter. The mutant forms of $N E F H$, pCAGEN eGFP-NEFH plasmid were obtained by site-directed mutagenesis using QuickChange II XL Mutagenesis Kit (from Agilent technology \#200521). Mutant NEFH plasmids harboring c.3008_3009delAA,
c.3043_3044delAA and c.3010_3011delGA are referred respectively as c3008, c3043 and c3010 in the text. Untagged NEFH plasmids (WT and CAE, c.3010_3011delGA mutation) and eGFP-NEFL plasmids were provided by $\mathrm{Pr}$ Zuchner (University of Miami, USA). Plasmids prepared with the EndoFree Maxiprep Kit (Macherey-Nagel, Düren, Germany) were routinely diluted at $2 \mu \mathrm{g} / \mu \mathrm{l}$.

\section{Cell line culture and transfection}

Human neuroblastoma cell line SH-EP $[3,6]$ were grown on $12 \mathrm{~mm}$ coverslips in Dulbecco's Modified Eagle Medium (DMEM, gibco) media supplemented with 10\% fetal bovine serum (FBS, Gibco) and 1\% penicillin/ streptomycin (Gibco) and transfected at $60 \%$ of confluence with jetPRIME (Polyplus-transfection) according to the manufacturer's protocol. 1, 2 or 3 days after transfection, cells were fixed with $4 \%$ paraformaldehyde for $20 \mathrm{~min}$, and washed with PBS.

\section{Primary motoneuron culture and transfection}

Spinal cord motoneurons were prepared from E12.5 OF1 mice embryos as described by Henderson et al. [14] with minor modifications. Briefly, anterior horn of the embryo were dissected in HBSS supplemented with $4.5 \mathrm{~g} / \mathrm{l}$ glucose and $7 \mathrm{mM}$ HEPES (invitrogen). Motoneurons were purified by using a $6 \%$ OptiPrep density gradient medium (D1556, Sigma). Then, motoneurons were resuspended in supplemented Neurobasal medium (Invitrogen) containing $1 \mathrm{ng} / \mathrm{ml}$ brain-derived neurotrophic factor (Peprotech), $1 \mathrm{ng} / \mathrm{ml}$ glial cell line-derived neurotrophic factor (Peprotech), and $10 \mathrm{ng} / \mathrm{ml}$ ciliary neurotrophic factor (Peprotech) and were seeded on polyornithin/laminin-coated glass coverslips (P8638 and L2020, Sigma). After two days in vitro, plasmid transfections were done by Magnetofection following the manufacturer recommendations (OZBiosciences). Two or four days later, motoneurons were fixed using 4\% paraformaldehyde for $20 \mathrm{~min}$, and washed with PBS.

\section{Embryonic chick spinal cord electroporation}

In ovo electroporation of chick embryos (Gallus gallus; EARL Morizeau, Dangers, France) was performed as previously described [26]. Briefly, the constructs were introduced into the lumen of neural tube at the caudal level in stage HH14-15 embryos [11]. Stage HH24-26 chick embryos were harvested and isolated in sterile phosphate-buffered saline (PBS) and defined fragments of the neural folds, where the eGFP expression was observed, were dissected, fixed in $4 \%$ paraformaldehyde and embedded in $7,5 \%$ gelatin $/ 15 \%$ sucrose, and frozen at $-40^{\circ} \mathrm{C}$ in isopentane. Twenty $\mu \mathrm{m}$ frozen tissue sections were performed for immunostaining analysis. 


\section{Immunocytochemistry}

Fixed cells or frozen tissue sections were blocked and permeabilized with PBS containing $4 \%$ bovine serum albumin, $2 \%$ goat serum, $100 \mathrm{mM}$ glycine and $0.3 \%$ Triton $\mathrm{X}-100$. Primary antibody was applied overnight at $4{ }^{\circ} \mathrm{C}$ diluted in blocking solution, washed 3 times in PBS, incubated for $2 \mathrm{~h}$ in the secondary antibody at room temperature, with DAPI, then washed four times in PBS, mounted in Vectashield ${ }^{\circ}$ and imaged with confocal microscope Zeiss LSM800 or imaged with conventional microscope Zeiss Axiovert $135 \mathrm{M}$ equipped with the camera Leica DC 350 FX CCD monochrome. The following antibodies were used: anti-acetylated tubulin (1/ 400, clone 6-11B-1, Sigma), anti p62 (1/200, GP62-C, Progen, Germany), anti-Ubiquitin conjugated protein1 (1/100, BML-PW8810, Enzo), anti - Lc3b (1/100, \#2775, Cell Signaling Technology, Danvers), anti-beta3 tubulin (1/500, TUJ1, Biolengend), anti-NEFM (1/500, Poly28410, Biolegend), anti-NEFH (1/2000, Smi32, Biolegend), anti-cleaved caspase 3 (1/100; 5A1E, Cell Signaling Technology, Danvers).

\section{Western blot}

Triton X100-soluble and -insoluble protein fractionation were performed following cell lysis in $20 \mathrm{mM}$ $\mathrm{NaCl}, 20 \mathrm{mM}$ Tris-HCl, pH 7.4, $5 \mathrm{mM} \mathrm{MgCl} 2,0.1 \mathrm{mM}$ EDTA, $0.1 \%$ Triton X-100, and protease cocktail, for $30 \mathrm{~min}$ at $4{ }^{\circ} \mathrm{C}$. Then, cell extracts were centrifuged for $15 \mathrm{~min}$ at $15000 \mathrm{~g}$ to separate soluble (supernatant) and insoluble (pellet) fractions. Pellet fraction was suspended in RIPA buffer. Soluble (S) and insoluble (I) fractions were resolved by SDS-PAGE and transferred on Nitrocellulose transfer membrane. Western blot was performed with anti-GFP (A11122, Thermo) and anti-GAPDH (2118 CST), followed by chemiluminescent detection using horseradish peroxidase-conjugated antibodies and the SuperSignal West Pico (Thermo Scientific) reagent.

\section{Statistical analysis}

Each experiment was repeated at least twice. Data were analysed with Excel (Microsoft) or SigmaStat 3.5 (Systat Software Inc). Data from more than two groups each showing normality and equal variance were analyse with one way ANOVA followed by Dunnett's test to compare several treatment group to a control group. Otherwise, data that do not showed a Gaussian distribution were analyse with one way Kruskal-Wallis test followed by Dunn posthoc test.

\section{Results}

\section{Clinical phenotype}

The clinical features of family 1 and 2 are summarized in Table 1.

\section{Family 1}

The affected siblings were born from non-consanguineous parents (Fig. 1a). The family displayed an autosomal dominant inheritance pattern. The propositus (III-3) was a 49-year-old woman. She had normal developmental milestones and no walking or running difficulties in childhood. At age 27, she developed difficulties climbing stairs. Muscle weakness worsened gradually and involved both distal and proximal muscles in the lower limbs, with difficulties arising from squat position. At 30 years of age, she developed proximal weakness in the lower limbs, involving particularly the iliopsoas muscle (MRC score $3 / 5$ ), in addition to the distal weakness. At age 49 , she was able to walk around $50 \mathrm{~m}$ with a walker, and used a wheelchair for longer distances. She was still able to climb stairs. Romberg's test showed mild postural instability. Heel or tiptoe walking was impossible. Squatting was impossible. Gower's manoeuvre was positive. Muscle strength examination showed a severe motor deficit in both proximal and distal muscles of the lower limbs (tibialis anterior $1 / 5$, peroneus longus and tibialis posterior muscles MRC 2/5 both sides; quadriceps 3/5 right side, $1 / 5$ left side; hamstring muscles $2 / 5$ both sides; gluteus medius $3 / 5$ both sides; iliopsoas $2 / 5$ both sides). There was distal motor deficit in the upper limbs (abductor digiti minimi 3/5 right side, $3+/ 5$ left side; normal strength in the other muscles). There were no fasciculations. There was distal and proximal muscle wasting in the lower limbs, and distal muscle wasting in the upper limbs. She had pes cavus. Deep tendon reflexes were absent and plantar reflex was flexor. She had distal hypoesthesia in the lower limbs (pin, touch and vibration). She reported frequent episodes of hypophonia, suggestive of associated vocal cord involvement. Cranial nerve examination was otherwise normal.

Other affected family members had normal milestones and could walk at normal ages (Table 1). Two of them had difficulties running and performing in gymnastics (III-3 and IV-1). Age of onset was around 50 years in generation I, 40 years in generation II, 30 years in generation III and 15 years in generation IV. Patients of the fourth generation had neither any symptoms (IV5 and IV6) nor reported running difficulties in childhood (IV1). On examination, they have mild symptoms such as mild distal lower limbs weakness, brisk or absent of lower limb deep tendon reflexes. They have been diagnosed early in their life since they were aware of symptoms related to the neuropathy in the family. Even mild neurological symptoms led their parents to seek for a neurological and neurophysiological exam confirming the neuropathy. Inaugural signs in most patients were progressive, distal lower-limbs muscles weakness and stepping gait. They progressively developed muscle wasting in the legs. Weakness and wasting in the proximal muscles of the lower limbs appeared within the third 


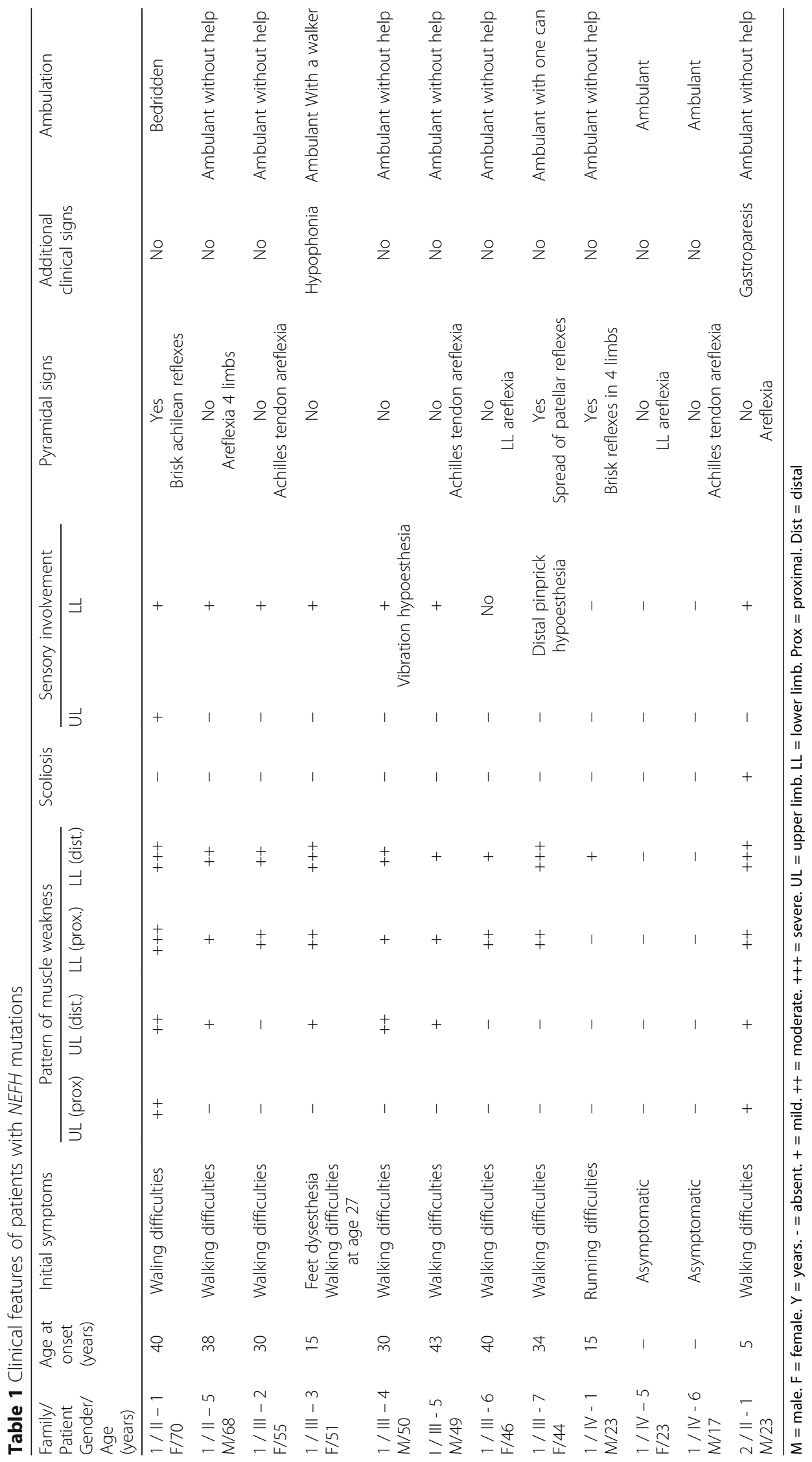


decade of the disease, and caused waddling gait. Motor deficit was clearly prominent in the iliopsoas whereas the quadriceps and hamstring muscles were better preserved during the third decade. However, the weakness spread over years to all proximal muscles in the lower and to distal muscles of the upper limbs. Indeed, the propositus's mother (patient II-1) presented at the age of 70 with diffuse motor weakness involving the distal and proximal muscles of the four limbs, associated with brisk reflexes. Most patients had cramps. Pes cavus was a consistent feature. Deep tendon reflexes absent in most patients, but three of them (II-1, III-7, IV-1) had brisk patellar reflexes. There was no Babinski or Hoffman sign. There were mild sensory abnormalities in all patients, with progressively ascending superficial and deep sensory alterations. The disease evolved progressively and most patients used a wheelchair around 50 years. There were no associated features such as visual loss, deafness, cranial nerve abnormalities, cerebellar syndrome, seizures or cognitive disturbances. One of the patients (III-4 of family 1) experienced a malignant hyperthermia following a surgical procedure.

\section{Family 2}

The propositus (II-1) was a 23-year-old man born from non-consanguineous asymptomatic parents (Fig. 1b). There was no familial history of neuropathy. He was born at term of an uncomplicated pregnancy. In early infancy, he presented with walking clumsiness with frequent falls and difficulties jumping. A pectum excavatum was noted. He had waddling gait with difficulties climbing stairs. Progressively, he developed drop foot gait and could not walk on heels. He had several episodes of ankle sprains. Since age 16, he developed progressive atrophy in the lower limbs muscles and complained of frequent cramps. At age 23, he could walk approximately one kilometre without help. He had waddling gait and bilateral foot drop. Heel or tiptoe walking and squatting were impossible. Gower's manoeuvre was positive. He had mild postural instability at Romberg's test. Muscle strength examination revealed a symmetric motor deficit in distal and proximal lower limbs (MRC score: tibialis anterior $1+/ 5$; soleus $1 / 5$, peroneus longus $0 / 5$, hamstring and gluteus medius $4 / 5$, quadriceps and psoas 3/5). Upper limbs examination showed symmetric proximal and distal deficit (distal hand muscles, biceps brachii and triceps brachii $4 / 5$ and deltoid 3/5). There was no axial deficit. There was severe muscle wasting in the lower limbs, distally and proximally, and Achilles tendons contractures. There were no fasciculations. He had bilateral scapular winging and pes cavus. Deep tendon reflexes were weak, plantar responses were flexor. He had distal hypoesthesia in the lower limbs (pin, touch and vibration). Neurological examination was otherwise normal. He had no associated features except for gastroparesia, with episodes of morning vomiting.

\section{Electrophysiological findings}

Nerve-conduction velocity studies are shown in Table 2 for families 1 and 2 . There was evidence of a motor and sensory axonal neuropathy predominantly affecting the lower limbs. EMG showed neurogenic changes in distal muscles in all patients and in proximal muscles in the most severely affected patients). Two patients (IV - 5 and IV - 6) in family 1 underwent an electrodiagnostic study before the genetic investigation at ages 23 and 17 years, respectively, which displayed a sensorimotor axonal neuropathy.

Table 2 Electrophysiological findings

\begin{tabular}{|c|c|c|c|c|c|c|c|c|c|}
\hline \multirow[b]{3}{*}{ Family/Patient } & \multicolumn{6}{|c|}{ Motor nerve conduction } & \multicolumn{3}{|c|}{ Sensory nerve conduction } \\
\hline & \multicolumn{2}{|c|}{ Median nerve } & \multicolumn{2}{|l|}{ Ulnar nerve } & \multicolumn{2}{|c|}{ Peroneal nerve } & \multirow{2}{*}{$\begin{array}{c}\text { Median nerve } \\
\text { Amp }(\mu \mathrm{V})\end{array}$} & \multirow{2}{*}{$\begin{array}{l}\text { Ulnar nerve } \\
\text { Amp }(\mu \mathrm{V})\end{array}$} & \multirow{2}{*}{$\frac{\text { Sural nerve }}{\text { Amp }(\mu \mathrm{V})}$} \\
\hline & Amp (mV) & $\mathrm{CV}(\mathrm{m} / \mathrm{s})$ & Amp (mV) & $\mathrm{CV}(\mathrm{m} / \mathrm{s})$ & Amp (mV) & $\mathrm{CV}(\mathrm{m} / \mathrm{s})$ & & & \\
\hline $1 / \|-5$ & 12.1 & 53.8 & NA & NA & 0.12 & 31.1 & NO & NO & NO \\
\hline $1 / \| I-2$ & 7.4 & 54.3 & NA & NA & 5 & 43.2 & 13.7 & NA & 4.5 \\
\hline $1 / I I \mid-3$ & 10.6 & 65 & 7.6 & 52 & 2.4 & 31 & 12 & 5 & 2 \\
\hline $1 /|| \mid-4$ & 8.2 & 50 & NA & NA & NA & NA & NO & NO & $\mathrm{NO}$ \\
\hline $1 / \| I-5$ & 6.4 & 45.1 & 8.5 & 49.8 & NO & NO & NO & NO & NO \\
\hline $1 /|| \mid-6$ & 7.8 & 44.2 & 11.4 & 50 & 2.4 & 30.8 & 6.3 & 3.3 & NO \\
\hline $1 / \| I-7$ & 3.4 & 51.1 & 9 & 43.6 & 4.1 & 41.1 & 4.2 & 7.7 & 4.5 \\
\hline $1 / \mathrm{IV}-1$ & 13.07 & 53 & 11.81 & 56 & 0.77 & 37 & 47.8 & 19.4 & 9.6 \\
\hline $1 / \mathrm{IV}-5$ & 8.2 & 55.2 & NA & NA & 5.8 & 39.1 & 10.1 & 10.3 & NO \\
\hline $1 / \mathrm{IV}-6$ & 8.0 & 50.2 & NA & NA & 6.5 & 38.5 & 11.5 & 14.7 & 4.1 \\
\hline $2 / \|-1$ & 5.77 & 54 & 6.8 & 59 & 1.35 & 34 & 3.5 & $\mathrm{NO}$ & NO \\
\hline
\end{tabular}

The right side of the nerves is represented in this table. Amp amplitude. CV conduction velocity. NO Not obtained. NA Not available 


\section{Histological findings}

Nerve biopsy of patient II-1 of family 1 showed signs of chronic denervation with no inflammatory infiltrates or vascular abnormalities. There was evidence of metachromatic staining of the Schwann cells. Muscle biopsy of patient III-3 of family 1 showed signs of chronic denervation associated with reinnervation. Some mitochondrial abnormalities were observed with mitochondrial loading in some fibers and three muscle fibers were Cox negative. Muscle biopsy of patient III-4 of family 1 showed muscle fiber atrophy with signs of chronic denervation and reinnervation. Cox staining was normal. Nerve biopsy of the same patient showed the rarefaction of large myelinated fibers and some fibers with thin myelin sheath (Additional file 1: Figure S1). There were no signs of inflammatory deposits or Congo red staining. Muscle biopsy of patient III-7 of family 1 showed muscle atrophy with signs of denervation following a fascicular distribution. Muscle biopsy of patient II-1 of family 2 showed atrophy and grouping of muscle fibers suggestive of neurogenic pattern. There were no mitochondrial abnormalities. Cox staining was normal.

\section{Molecular analysis}

In family 1 , only one $N E F H$ variant was shared by the four patients, and absent in ExAC database. In family 2, 30 variants absent in ExAC database were found for the index case. The variant in NEFH was the only one absent in his two parents. Both variants were novel deletions of 2 nucleotides in the extreme C-terminus of NEFH gene: in family 1, c.3008_3009del (p.Lys1003Argfs*59), and in family 2 c.3043_3044del (p.Lys1015Glyfs*47). The segregation of the mutation in family 1 was confirmed in 13 at-risk subjects (11 affected, 2 no affected). The mutation occurred de novo in family 2.

\section{Mutant NEFH forms aggresomes in human neuroblastoma cells line}

Both mutations cause the loss of the termination codon, leading to the translation of 40 additional amino acids until the next stop codon at the 3'UTR, as described in Rebelo et al. (c.3010; Fig. 2a). We thus investigated whether our mutations could cause protein aggregation. Expression vectors for eGFP tagged NEFH were transfected in the human neuroblastoma cell line SH-EP. Twenty-four hours after transfection all mutant forms (c.3008, c.3043 and c.3010) formed aggregates visible at $10 \times$ lens objective in more than $70 \%$ of the transfected cells, without significant difference between c.3008 (70.6\% +/ - 6.7), c.3043 (78.3 +/- 8.0) or c.3010 (72.3\% $+/-4.9)$ (Fig. 2c). Conversely, WT NEFH formed aggregates in less than $1 \%$ of the transfected cells $(0.3 \%+/-$ $0.6)$. This result was consistent with the one obtained by Rebelo et al.
Next we investigate the subcellular distribution of mutant NEFH proteins, forty-eight hours after transfection. At low expression levels, WT NEFH incorporated into a filamentous network in the cytoplasm (Additional file 2: Figure S2). At higher plasmid concentration, overexpressed WT NEFH was distributed homogenously in the cytoplasm as revealed by the co-staining with acetylated tubulin and DAPI (Fig. 2b). Conversely, mutant NEFH proteins was always found under the plasma membrane and was also either localized in small aggregates scattered over the cytoplasm or accumulated in a single prominent perinuclear aggregate next to the microtubule organization center (MTOC). Such prominent perinuclear inclusion bodies formed next to the MTOC are commonly named aggresomes [18]. Accumulation of insoluble proteins is characteristic of aggresomes. Solubility in Triton X-100 was used to evaluate the solubility of NEFH proteins expressed in SH-EP cells. As shown in Fig. 2d, WT NEFH was solubilized by $0.1 \%$ Triton, whereas a significant proportion of mutant NEFH proteins were insoluble. Aggresomes are also characterized by accumulation of ubiquitin conjugates. As expected, aggregates of mutant NEFH proteins colocalized with mono- and poly-ubiquitinated conjugates as evidenced by staining of ubiquitin conjugated (Fig. 3a).

\section{Mutant NEFH proteins are addressed to the autophagic pathway}

Aggresome formation has been proposed to allow isolation of toxic misfolded proteins and to act as key step for the disposal of protein aggregates by autophagy. In addition, the autophagy role in motoneuron and muscle disorders associated with protein aggregates is well known $[5,7,29]$. We thus investigated the distribution of the protein $\mathrm{p} 62 / \mathrm{SQSTM}$ that recruits poly ubiquitinated substrates to autophagy. Immunofluorescence experiments revealed that p62 colocalized with aggresomes containing mutant NEFH (Fig. 3b). Finally, we examined the distribution of LC3b, an autophagosome marker. Consistently with p62 localization, we found that LC3b accumulated with aggresomes containing mutant NEFH proteins (Fig. 3c). Altogether, these observations suggest that the cells sequester mutant NEFH proteins in aggresomes from where they direct them to autophagy for degradation.

NEFH mutants perturb the neurofilament network in vitro The ability of NEFH mutants to form an aggresome in the presence of a dense intermediate filamentous network containing the NEFH partner NEFL was investigated. Monomeric eGFP tagged NEFL, untagged NEFH WT or untagged NEFH CAE mutants (referring to the mutant c.3010_3011DelAG, Rebelo et al.) were overexpressed in SH-EP cells, alone or in combination. As expected, SH-EP expressing eGFP-NEFL formed a typical filamentous network. In agreement with the results presented above, WT 
a

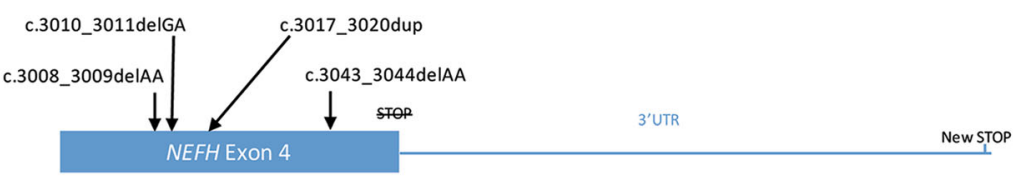

$\stackrel{20}{120}$

40

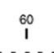

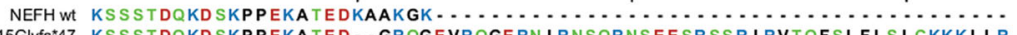
p.Lys1015Glys'47 KSSSTDQKD SKPPEKATED -. GRQGEVRQGERN IRNSQRNSEESRSSR IRVTQFSLFLSLCKKKLLR p.Lys1003Argfs'59 KSSSTDQR - Q QAASREGHRRQGRQGEVRQGERN IRNSQRNSEESRSSRIRVTQFSLFLSLCKKKLLR p.Asp1004Glins'58 KSSSTDQK...QQASREGHRRQGRQGEVRQGERN IRNSQRNSEESRSSRIRVTQFSLFLSLCKKKLLR

b
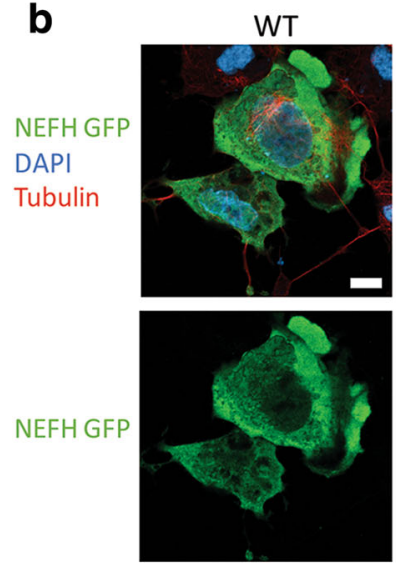

C

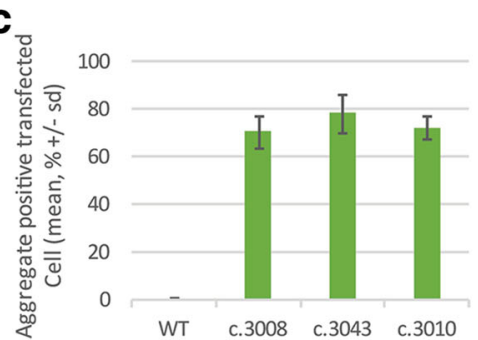

C.3008
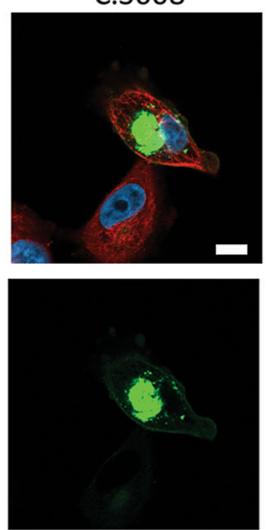

d

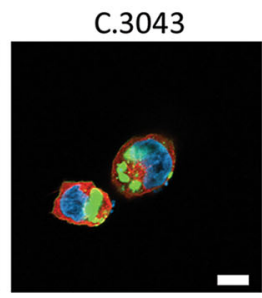

CAE
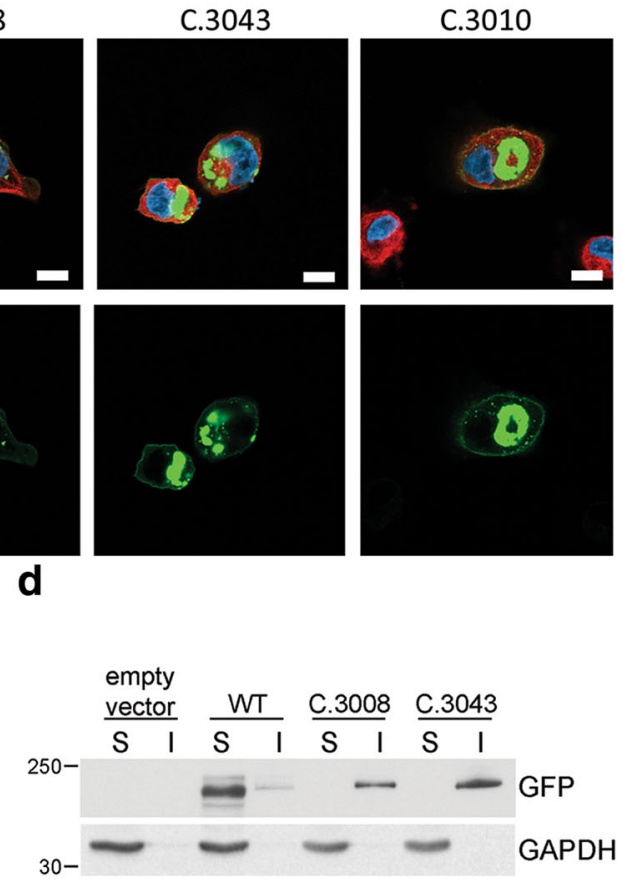

Fig. 2 NEFH mutations cause protein aggregation in SH-EP. a Amino acid alignment of normal and mutant NEFHC-terminal parts reported in the CMT2cC presenting the Cryptic Amyloidogenic Element translation and their differences. Amino acid color correlates with polarity: hydrophobic in black, hydrophilic in green, acidic in red and basic in blue. $\mathbf{b}$ Confocal images of SH-EP transfected with EGFP tagged NEFH vectors and counterstained for tubulin in red and nucleus (DAPI) in blue. Scale bar: 20 mm. c Quantification of SH-EP cells with protein aggregates. Values represent mean +/- standard deviation of 15 fields, repeated in triplicates and analyzed by one-way ANOVA on ranks followed by Dunn posthoc test $(P<0.001)$. d $0.1 \%$ Triton $X-100$ Soluble and Insoluble fractionation revealed by western-blotting using GFP antibody to stain NEFH fusion protein and GAPDH gene to normalize

NEFH homogenously distributed in the cytoplasm whereas NEFH CAE mutants formed perinuclear aggregates, as revealed by the Smi32 staining (Fig. 4a). As expected, eGFP-NEFL and WT NEFH colocalized in a dense filamentous network in SH-EP cells (Fig. 4b). Interestingly, eGFP-NEFL and mutant NEFH-CAE proteins colocalized restrictedly in an aggresome containing p62/SQSTM1 and LC3b (Fig. 4b). Therefore, NEFH mutants not only form aggresomes, but also interact with NEFL and destabilizes the neurofilaments network.

\section{Mutant NEFH proteins activate caspase 3 dependent cell death in vitro}

Aggresome formation usually indicates a cellular stress response. To determine if mutant NEFH could be cytotoxic, we investigated for signs of cellular stress. $\mathrm{NEFH}$ is a key component of intermediate filaments that contribute to the formation of the cytoskeleton. We thus first examined the morphology of transfected cells $24 \mathrm{~h}$ after transfection. Metamorph analysis of the morphology of more than 1000 cells chosen stochastically demonstrated that cells expressing mutant NEFH presented a significantly reduced average radius and a significantly increased average shape factor compared to cells expressing WT NEFH (Additional file 3: Figure S3). Together, this indicated that cells expressing mutant NEFH are smaller and rounder.

We next examined whether mutant NEFH proteins could alter cell viability. Caspase 3 is activated by proteolytic cleavage by both extrinsic (death ligand) and intrinsic 


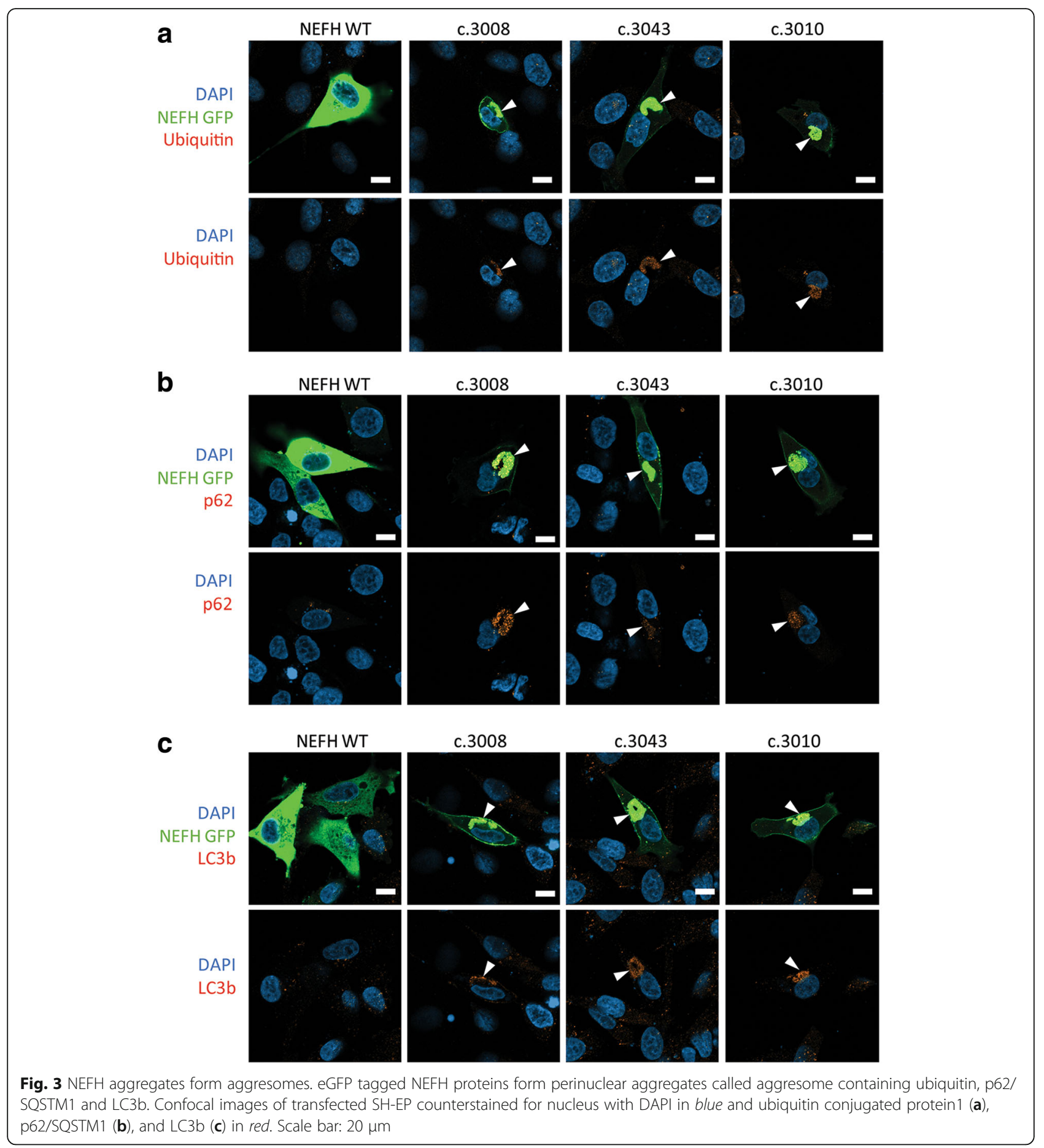

(mitochondrial) apoptotic pathways. Immunofluorescence experiments detected caspase 3 activation in numerous cells $48 \mathrm{~h}$ after transfection with one of the mutant NEFH expression vectors. Caspase 3 activation was often associated with a pyknotic nuclei, indicating ongoing apoptosis (Fig. 5a). Quantification of the percentage of cells containing activated caspase 3 at different times points after transfection revealed a progressive increase of the number of cells triggering the apoptotic pathway. Approximately $10 \%$ of SH-EP cells expressing a mutant NEFH had activated caspase 3 twenty four hours after transfection, this number increasing to $25 \%$ and $50 \% 48 \mathrm{~h}$ and $72 \mathrm{~h}$ after transfection, respectively (Fig. 5b).

To confirm that mutant NEFH triggered cell death overtime, we used propidium iodide (PI), a fluorescent intercalating agent that requires broken membranes to reach 
a

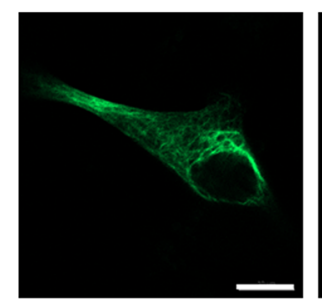

b
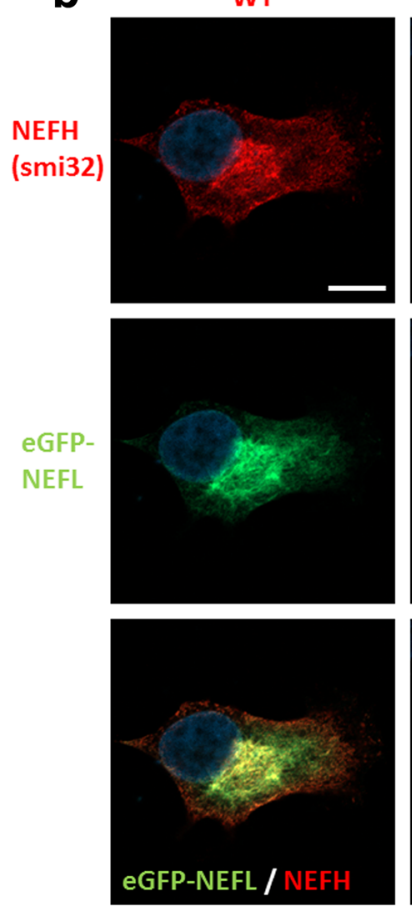

NEFH wt (Smi32)

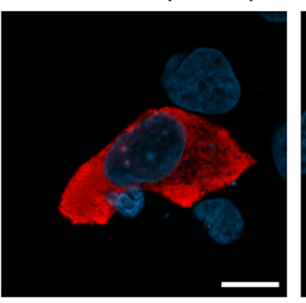

CAE
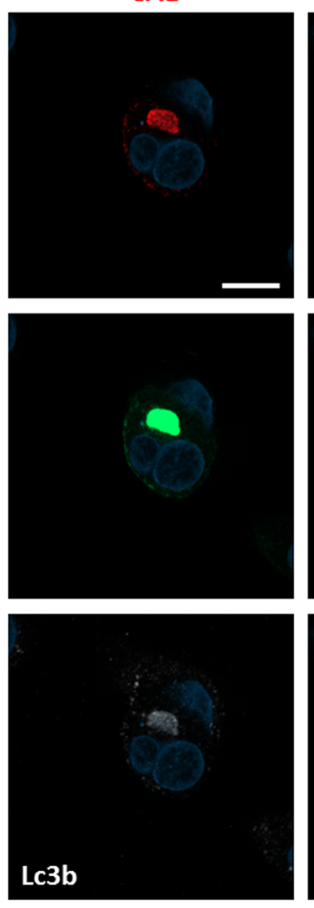

\section{NEFH CAE (Smi32)}

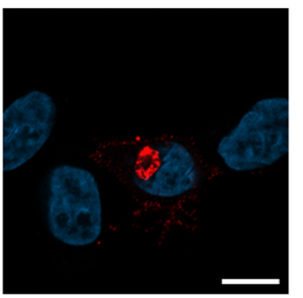

CAE
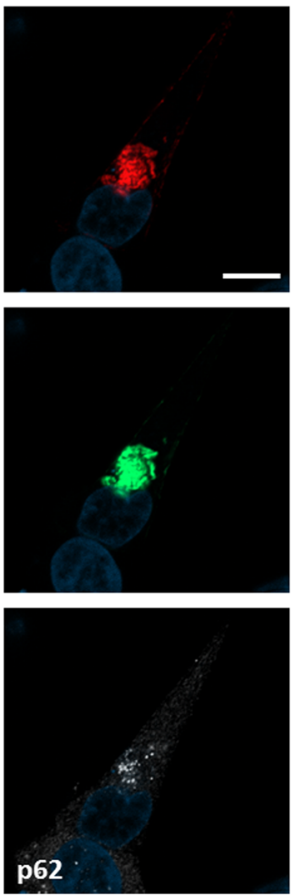

Fig. 4 NEFH mutation destabilised NEFL filamentous network in vitro. a Confocal images of transfected SH-EP with eGFP-NEFL or untagged NEFH WT or untagged NEFH-CAE (c3008_3010delGA mutation). Untagged NEFH proteins were stained using anti-NEFH antibody Smi32. Scale bar: $10 \mu \mathrm{m}$. b Confocal images of co-transfected SH-EP with eGFP-NEFL and untagged NEFH WT or CAE. The mutant untagged NEFH-CAE proteins form aggresome containing NEFL, p62/SQSTM1 and LC3b. Scale bar: $10 \mu \mathrm{m}$

nuclear DNA and thus selectively labels dying cells. Twenty-four hours after transfection with a mutant NEFH vector, $6 \%$ of cells were stained positive for PI, and $25 \%$ of cell were stained 1 day later, consistently with caspase 3 activation results (Fig. $5 \mathrm{c}$ ). Altogether, these results show that expression of mutant NEFH strongly triggered caspase 3 activation and cell death.

\section{Mutant NEFH form aggresomes in primary motoneurons in vitro}

To confirm our observation in motoneurons, mouse primary motoneuron cultures were used [14, 16, 17] (Additional file 4: Figure S4). Two days after magnetofection, WT and mutant eGFP-NEFH formed a filamentous network with endogenous NEFL (Fig. 6a). Interestingly, after 2 days of expression mutant eGFP-NEFH formed aggregates along the filamentous structure, which evolved in a prominent perinuclear aggresome containing LC3b as observed 4 days after magentofection (Fig. $6 \mathrm{a}$ and b).

NEFH mutations cause protein aggregation and apoptosis in spinal cord neurons

In order to evaluate the effect of NEFH mutations in vivo on spinal cord neurons, we decided to express NEFH in the spinal cord of chick embryos by in ovo electroporation. Electroporation of embryonic hemi neural tube allows transfer of expression vectors in both motor neurons and dorsal root ganglion (DRG) sensitive neurons. Confocal images of the entire spinal cord showed that transfection was efficient in the hemi spinal cord neurons (Fig. 7a) and less efficient in the DRG but still sufficient to visualize some electroporated neurons (data not show). At 

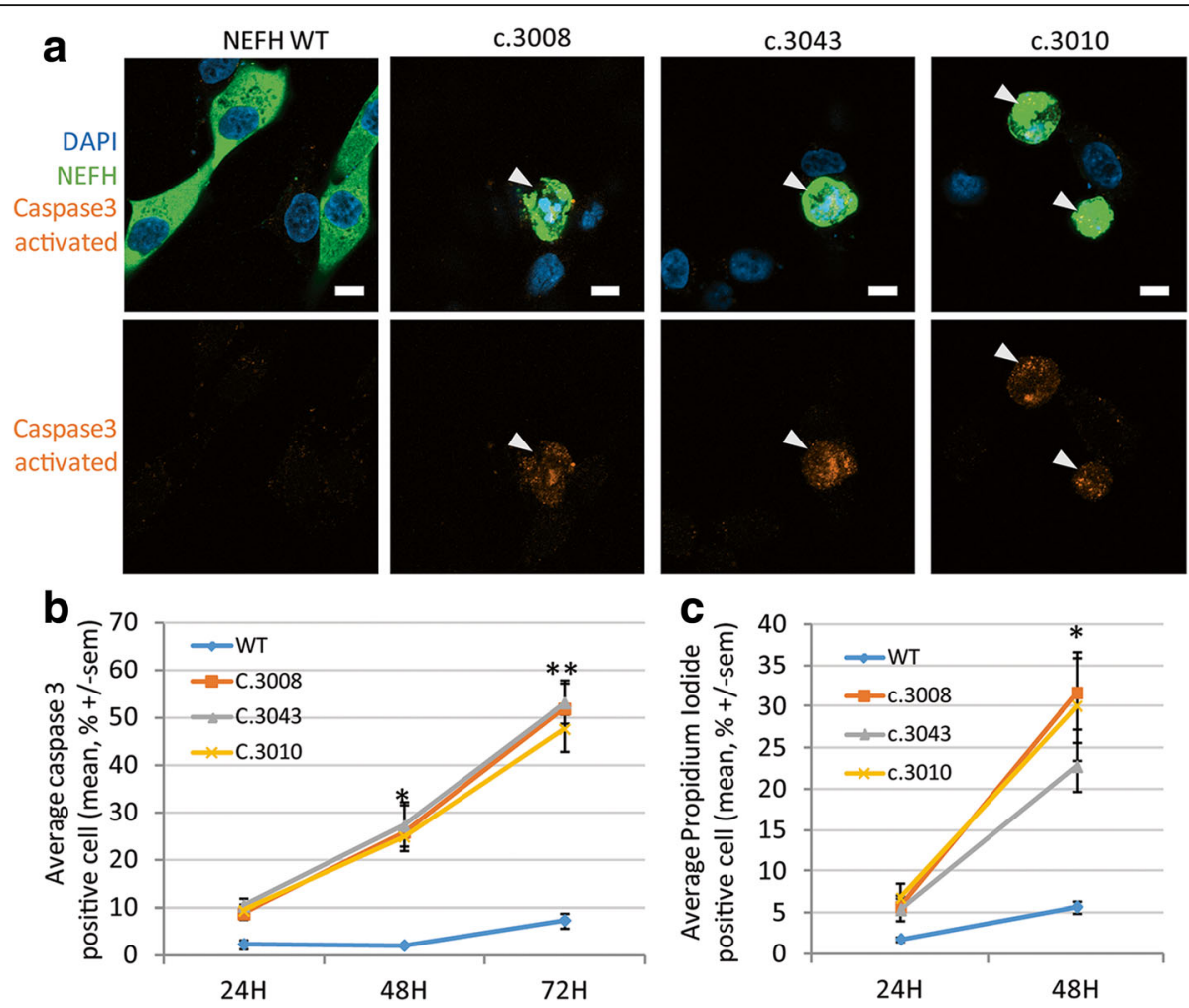

Fig. 5 NEFH mutations trigger caspase 3 dependent death in vitro. a Confocal images of transfected SH-EP counterstained with DAPI in blue and activated caspase 3 in red. Scale bar: 20 mm. b Percentage of caspase 3 activated positive cells overtime. Values represent means $+/-$ sem from at least three independent experiment analyzed by one way ANOVA followed by multiple comparisons versus control group (Dunnett's Method) ${ }^{*} p<0.02 ;{ }^{* *} p<0.001$. c Quantification of the percentage of propidium iodide permeable cells. Values represent means $+/$ - sem from at least three independent experiment analyzed by one way ANOVA followed by multiple comparisons versus control group (Dunnett's Method) ${ }^{*} p<0.02$

higher magnification the anterior horn of these sections holding motor neurons revealed that WT NEFH distributed in a filamentous network (Additional file 2: Figure S2C). Conversely, mutant NEFH proteins accumulated at intense foci in the soma of the neurons forming aggresomes which colocalized with p62/SQSTM1 and LC3b (Fig. 6b). Caspase 3 activation was clearly detected in $0.22 \%+/-0.02$ and $0.25 \%+/-0.03$ neurons electroporated with mutant NEFH constructs c.3008 and c.3043 respectively (Fig. 7c). In these neurons, the occurrence of Caspase 3 activation $48 \mathrm{~h}$ after electroporation was more than 8 fold higher than in neurons expressing the WT NEFH expression construct (Fig. 7d). Progressive apoptosis activation is consistent with the neurodegenerative features observed in the patients.

\section{Discussion and conclusions}

The families presented here displayed a severe, predominantly motor, axonal autosomal dominant form of CMT with proximal motor involvement in the lower limb associated with two previously unreported mutations in the NEFH gene, including a de novo mutation. The clinical phenotype varied in term of age at onset, ranging from 5 to 40 years, with a median around 30 years. A remarkable and consistent feature in all patients was the early involvement of proximal muscles of the lower limbs, occurring approximately 10 to 15 years after the onset of motor deficit. Proximal deficit involved predominantly the iliopsoas muscle, whereas quadriceps and hamstring muscles were relatively preserved. Proximal muscles weakness is rare in any form of CMT. Proximal lower-limb weakness with waddling gait is also described in recessive forms of CMT due to NEFL mutations [2]. There was muscle wasting predominant in the distal lower limbs muscles progressively ascending to proximal limbs muscles and distal upper limbs muscles. Muscle weakness and muscle wasting were quickly evolving, with most of the patients needing walking assistance after 20 years of disease evolution. Three patients in family 1 had brisk reflexes associated with distal and proximal weakness. Pyramidal signs have also been shown in CMT caused by NEFL mutations $[2,13]$. The phenotype was mainly motor but there were also sensory alterations, with prominent involvement of large sensory nerves. There were no associated features except for gastroparesia in one patient and vocal cord involvement in another patient. Muscle pathology and electrophysiological studies were consistent with a symmetrical, 


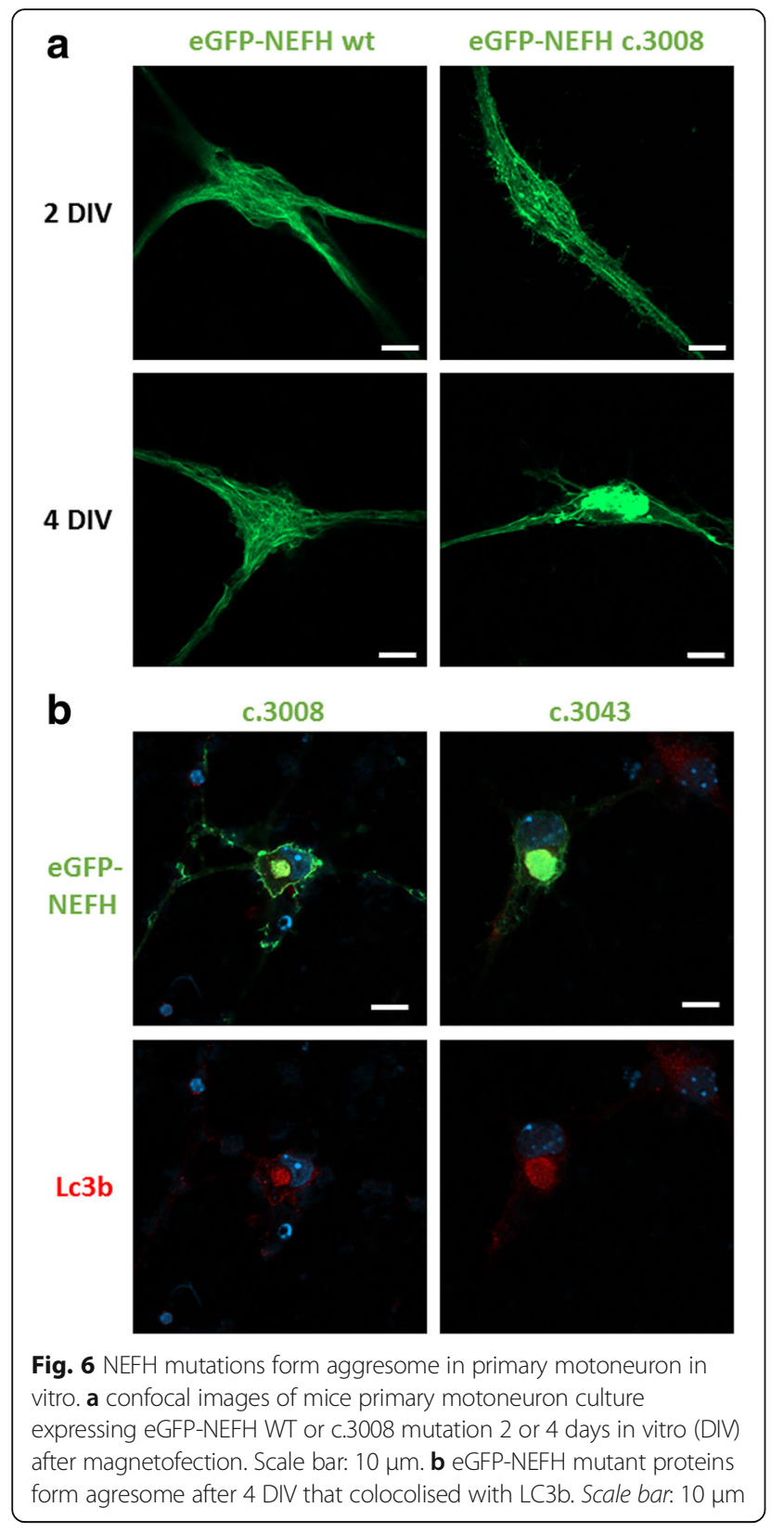

progressive distal and proximal sensorimotor axonal neuropathy. These findings are in accordance with the previously published paper [27]. It is worth noticing that electrophysiological studies of two asymptomatic patients of family 1 (IV5, IV6) showed a sensorimotor neuropathy respectively at the age of 23 and 17 years, indicating that the neuropathy may exist in a latent state. Patients of these IV generation have been diagnosed early in their life since they were aware of symptoms related to the neuropathy in the family. Although we could not exclude the hypothesis of an anticipation, it must be stressed that even mild neurological symptoms led their parents to seek for a neurological and neurophysiological exam that would confirm the neuropathy.

The pathogenicity of the NEFH mutations was confirmed by the easy segregation of the mutation in both families. The clinical phenotype was also very similar in the two families. Analysis of family 1 suggests an anticipation pattern given that the proband had an earlier age of onset and more severe manifestations than did the previous generations. This anticipation pattern has already been reported in the previously reported patients [27]. Nevertheless, this anticipation phenotype is probably rather due to a diagnostic bias than to biological phenomenon. Indeed, in families with known familial CMT, clinical signs of the disease are searched earlier and thus detected sooner in the offsprings. The penetrance of the disease appeared to be complete. Muscle weakness was more severe in patient II-1 of family 2, who carries a de novo mutation in NEFH gene, than in patients belonging to family 1 at the same age. The two previously reported families had frameshift variants in the extreme C-terminus of NEFH [27]. Our two families present with original deletions of two nucleotides close to the normal stop codon. Mutation in family 1 (c.3008_3009delAA; p.Lys1003Argfs*59) leads to the same defective protein as in family UK1 at the exception of one amino acid. Mutation in family 2 is located just three amino acids before the normal stop codon, and is the most subterminal variant in the four families reported thus far. Both mutations translate into the same alternative Open Reading Frame (ORF), which is also identical to the previously reported families [27].

The predominance of motor involvement in both proximal and distal muscles associated with brisk reflexes in some members of family 1 initially prompted us to study the SOD1 gene implicated in genetic ALS, but no mutation was found. In ALS, there is accumulation of neurofilaments in motor neurons. Mouse models with overexpression of neurofilaments subunits have a motor neuropathy resembling ALS [20]. Rare mutations in the peripherin and in the KSP repeats motifs have been reported $[1,8]$, and a latter study showed that a short allele of the NEFH tail was associated with ALS [30]. Other studies found no mutations of NEFH in ALS $[9,28]$. The pathogenicity of NEFH mutations in ALS thus remains unclear. Nevertheless, the proposed association of $N E F H$ mutations with ALS and the finding that some CMT patients with NEFH mutations have unusual clinical signs related to ALS is intriguing and consistent with the notion that mutations causing the addition of a cryptic amyloidogenic element to NEFH proteins cause a particular neuropathy with overlapping clinical features of both CMT and ALS.

Our in vitro and in vivo experiments provide a rational basis to these observations by demonstrating that $N E F H$ 


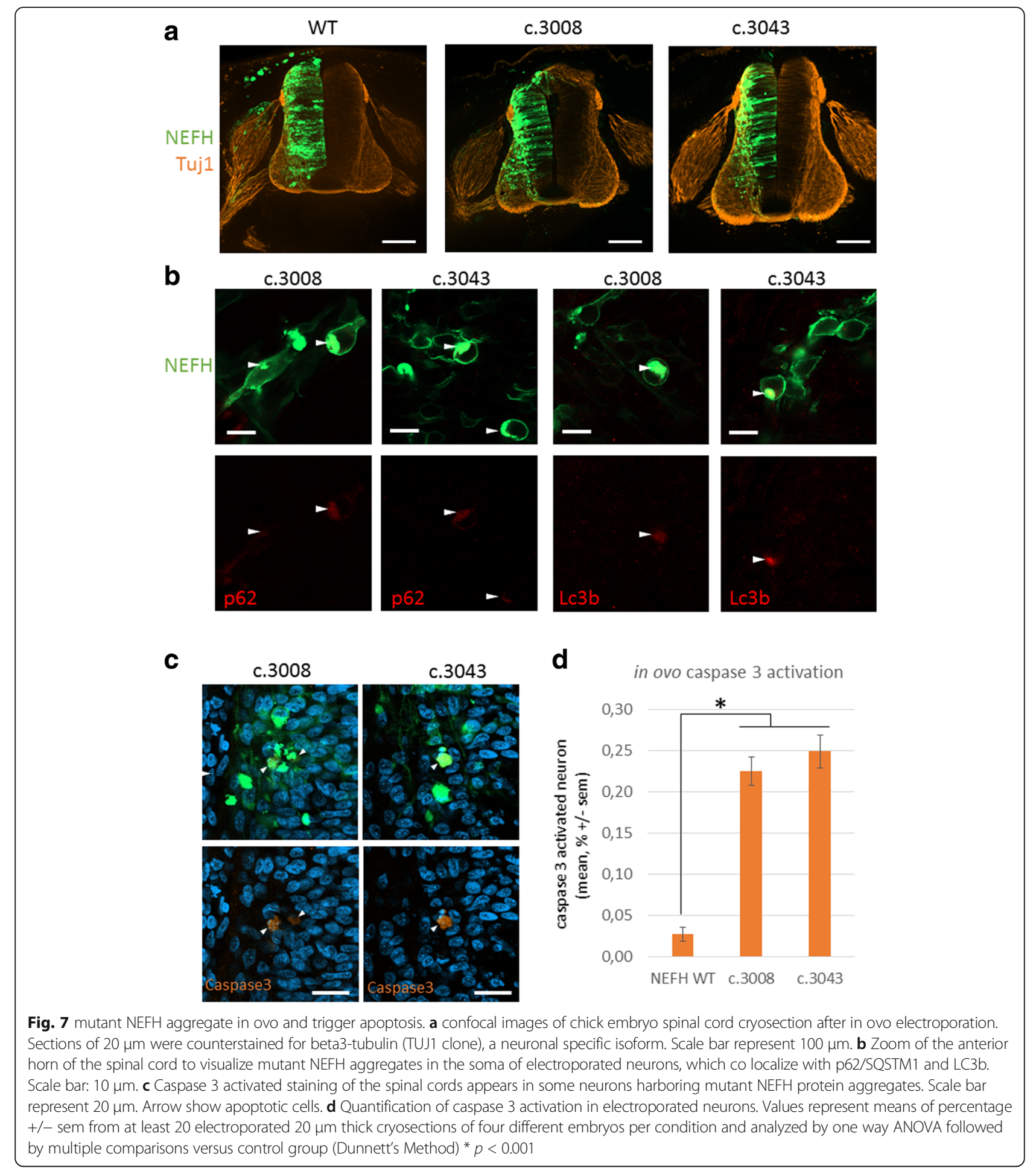

mutations causing the addition of a CAE induce aggresome formation and neuronal apoptosis. Loss of motor neurons is a hallmark of ALS, which is also increasingly associated with the presence of protein aggregates in motoneurons. This is especially true for ALS caused by mutations in SOD1, TDP43 and C9ORF72 [32]. The presence of intracellular protein inclusions is a common hallmark of a wide variety of human disorders. These include neurofibrillary tangles in Alzheimer's disease, Lewy bodies in Parkinson's disease, polyglutamine enriched inclusions in Huntington's disease, as well as intermediate filament inclusions in specific myopathies. Once formed, 
protein aggregates tend to be insoluble, refractory to proteolysis and to accumulate in inclusion bodies which are usually present in low copy number, most often only one per cell [18]. This is consistent with the features of the NEFH protein aggregates we observed, which mostly accumulated in one spot and contained insoluble proteins.

Autophagy is the major cellular process by which large cytoplasmic components, including ribosomes, organelles and protein aggregates, are degraded. Autophagy plays a key role in the maintenance of homeostasis and the quality of the cellular component for the survival of the neuron in their functional context. The finding that the autophagy proteins p62 and LC3 are present in $\mathrm{NEFH}$ aggregates indicates that the presence of the CAE triggers autophagy. Although the precise role of autophagy in motoneuron disease is unclear, emerging evidence supports the notion that defects in autophagic pathway may contribute to pathogenic mechanism and could constitute valuable therapeutic targets $[5,7,22,31]$.

Mutations in NEFH cause a sensorimotor axonal neuropathy, characterized by distal lower limbs motor deficit with early and prominent involvement proximal of the iliopsoas muscle, associated in some patients with pyramidal signs. Clinical features of NEFH mutations clearly overlap with those of motor neuron disease. At the cellular level, mutant NEFH is sequestered in a prominent perinuclear inclusion body, the aggresome which is addressed to the autophagic pathway. Mutant NEFH proteins are nevertheless toxic and progressively trigger caspase 3 dependant apoptosis. Interestingly, motoneuron death and intracellular protein inclusions are common hallmarks in ALS. Characterization of cellular effects of the NEFH mutations provides a rational basis to the clinical continuum between CMT and ALS in affected patients.

\section{Additional files}

Additional file 1: Figure S1. Superficial peroneal sensory nerve biopsy (case III4): Semi-thin section. A. Note the rarefaction of large myelinated fibers. B. Several fibers have a thin myelin sheath (arrowhead) and some of them present myelin sweling (arrow). (Original magnification $\times 100$ ). (PNG $947 \mathrm{~kb}$ )

Additional file 2: Figure S2. eGFP-NEFH WT form filamentous network in vitro and in ovo. A. monomeric eGFP tag NEFH WT expression can form visible filamentous network in SH-EP under lower expression condition when transfected at low concentration (optimal recommended concentration diluted four time). eGFP-NEFH WT form filamentous network in spinal motoneuron in vitro (B) and in vivo (C). Scale bar $10 \mu \mathrm{m}$. (TIFF $156 \mathrm{~kb})$

Additional file 3: Figure S3. NEFH mutations modify cell morphology in vitro. A Mutant NEFH expression induces morphological changes as seen on 10x microscopic images. Scale bar represent $100 \mu \mathrm{m}$. B-C. Quantification of the average shape factor and radius of transfected SH-EP cells. Values represent means in percent $+/-$ standard deviation of at least 15 fields (Cells analyzed $>1000$ per condition) and analyzed by KruskalWallis one way ANOVA on ranks test followed by Dunn's methods $(* P<0.001)$. Shape factor equal to one usually represents an ideal circle. (PNG $334 \mathrm{~kb})$
Additional file 4: Figure S4. Representative primary motoneuron in its entirety in vitro. A Non transfected motoneuron revealed by SMI-32 staining. B. Magnetofected motoneuron with eGFP tag NEFH WT or mutated form, without counterstaining. (PNG $156 \mathrm{~kb}$ )

Acknowledgements

We thank Aurora Pignata for her technical help on chick embryo experiment.

Funding

AJ was funded by ADN "Association pour le Développement de la Neurogénétique". SZ is the recipient of NIH R01NS072248 and NIH U54NS092091 (CReATe).

\section{Authors' contributions}

TS, CD, OD, GS, MG and RJ did the clinical assessment. TS and CD performed clinical meta-analysis. PL was in charge of the molecular analysis of the patients. AJ and LS designed experimental studies in vitro and in ovo. AJ and EB performed the in vitro studies. AJ and VC performed the in ovo studies. AJ, LS, TS, PL, SZ, AR and AA wrote the paper. All authors read and approved the final manuscript.

\section{Ethics approval and consent to participate}

All procedures performed in studies involving human participants were in accordance with the ethical standards of the institutional and/or national research committee and with the 1964 Helsinki declaration and its later amendments or comparable ethical standards. Informed consent was obtained from all individual participants included in the study. All procedures performed in studies involving animals were in accordance with the ethical standards of the institution or practice at which the studies were conducted.

\section{Competing interests}

The authors declare that they have no competing interests.

\section{Publisher's Note}

Springer Nature remains neutral with regard to jurisdictional claims in published maps and institutional affiliations.

\section{Author details}

${ }^{1}$ Institut NeuroMyoGène, Université Lyon1 - CNRS UMR 5310 - INSERM U1217, Lyon, France. 'Unité fonctionnelle de neurogénétique moléculaire, $\mathrm{CHU}$ de Lyon - HCL groupement Est, Bron, France. ${ }^{3}$ Département de Neurologie, Hôpital Pitié-Salpêtrière, Paris, France. ${ }^{4}$ Clinique du motoneurone et pathologies neuromusculaires, CHRU de Montpellier, Montpellier, France. ${ }^{5}$ Centre de références des maladies neuromusculaires, $\mathrm{CHU}$ de Bordeaux, Bordeaux, France. ${ }^{6}$ Centre de référence des maladies neuromusculaires, Hôpital Pitié-Salpêtrière, Paris, France. ${ }^{7}$ Service de Neurologie, $\mathrm{CH}$ de Valenciennes, Valenciennes, France. ${ }^{8}$ Institut de pathologie, CHU de Lille, Lille, France. ${ }^{9} \mathrm{Dr}$ John T. MacDonald Foundation Department of Human Genetics, Institute of Human Genomics, University of Miami, Miller School of Medicine, Miami, USA. ${ }^{10}$ Institut de Myologie, Hôpital Pitié-Salpêtrière, 47-83 boulevard de l'Hôpital, 75013 Paris, France. ${ }^{11}$ Centre de Biotechnologie Cellulaire, CBC Biotec, CHU de Lyon - HCL groupement Est, Bron, France.

Received: 27 June 2017 Accepted: 28 June 2017

Published online: 14 July 2017

\section{References}

1. Al-Chalabi A, Andersen PM, Nilsson P, Chioza B, Andersson JL, Russ C, Shaw CE, Powell JF, Leigh PN (1999) Deletions of the heavy neurofilament subunit tail in amyotrophic lateral sclerosis. Hum Mol Genet 8:157-164

2. Berciano J, García A, Peeters K, Gallardo E, Vriendt ED, Pelayo-Negro AL, Infante J, Jordanova A (2015) NEFL E396K mutation is associated with a novel dominant intermediate Charcot-Marie-Tooth disease phenotype. J Neurol 262:1289-1300. doi:10.1007/s00415-015-7709-4

3. Biedler JL, Helson L, Spengler BA (1973) Morphology and growth, tumorigenicity, and cytogenetics of human neuroblastoma cells in continuous culture. Cancer Res 33:2643-2652

4. Carter J, Gragerov A, Konvicka K, Elder G, Weinstein H, Lazzarini RA (1998) Neurofilament (NF) assembly; divergent characteristics of human 
and rodent NF-L subunits. J Biol Chem 273:5101-5108. doi:10.1074/jbc 273.9.5101

5. Chen S, Zhang X, Song L, Le W (2012) Autophagy dysregulation in amyotrophic lateral sclerosis. Brain Pathol Zurich Switz 22:110-116. doi:10. 1111/j.1750-3639.2011.00546.x

6. Ciccarone V, Spengler BA, Meyers MB, Biedler UL, Ross RA (1989) Phenotypic diversification in human neuroblastoma cells: expression of distinct neural crest lineages. Cancer Res 49:219-225

7. Cipolat Mis MS, Brajkovic S, Frattini E, Di Fonzo A, Corti S (2016) Autophagy in motor neuron disease: key pathogenetic mechanisms and therapeutic targets. Mol Cell Neurosci 72:84-90. doi:10.1016/j.mcn.2016.01.012

8. Figlewicz DA, Krizus A, Martinoli MG, Meininger V, Dib M, Rouleau GA, Julien J-P (1994) Variants of the heavy neurofilament subunit are associated with the development of amyotrophic lateral sclerosis. Hum Mol Genet 3:1757-1761

9. Garcia ML, Singleton AB, Hernandez D, Ward CM, Evey C, Sapp PA, Hardy J, Brown RH, Cleveland DW (2006) Mutations in neurofilament genes are not a significant primary cause of non-SOD1-mediated amyotrophic lateral sclerosis. Neurobiol Dis 21:102-109. doi:10.1016/j. nbd.2005.06.016

10. Gutmann L, Shy M (2015) Update on Charcot-Marie-Tooth disease. Curr Opin Neurol 28:462-467. doi:10.1097/WCO.0000000000000237

11. Hamburger $V$, Hamilton $\mathrm{HL}$ (1992) A series of normal stages in the development of the chick embryo. 1951. Dev Dyn Off Publ Am Assoc Anat 195:231-272. doi:10.1002/aja.1001950404.

12. Harding AE, Thomas PK (1980) The clinical features of hereditary motor and sensory neuropathy types I and II. Brain J Neurol 103:259-280

13. Hashiguchi A, Higuchi $Y$, Nomura M, Nakamura T, Arata H, Yuan J, Yoshimura A, Okamoto Y, Matsuura E, Takashima H (2014) Neurofilament light mutation causes hereditary motor and sensory neuropathy with pyramidal signs. J Peripher Nerv Syst 19:311-316

14. Henderson CE, Bloch-Gallego E, Camu W Purified embryonic motoneurons. In: Cohen J, Wilkin G (eds) Nerve cell cult. Pract. Approach, Oxford Univ. Press, London, pp 69-81

15. Hoffman PN, Cleveland DW, Griffin JW, Landes PW, Cowan NJ, Price DL (1987) Neurofilament gene expression: a major determinant of axonal caliber. Proc Natl Acad Sci U S A 84:3472-3476

16. Jacquier A, Bellouze S, Blanchard S, Bohl D, Haase G (2009) Astrocytic protection of spinal motor neurons but not cortical neurons against loss of Als2/alsin function. Hum Mol Genet 18:2127-2139. doi:10.1093/hmg/ddp136

17. Jacquier A, Buhler E, Schäfer MK, Bohl D, Blanchard S, Beclin C, Haase G (2006) Alsin/Rac1 signaling controls survival and growth of spinal motoneurons. Ann Neurol 60:105-117. doi:10.1002/ana.20886.

18. Johnston JA, Ward CL, Kopito RR (1998) Aggresomes: a cellular response to misfolded proteins. J Cell Biol 143:1883-1898

19. Jordanova A, Jonghe PD, Boerkoel CF, Takashima H, Vriendt ED, Ceuterick C, Martin J-J, Butler IJ, Mancias P, Papasozomenos SC, Terespolsky D, Potocki L, Brown CW, Shy M, Rita DA, Tournev I, Kremensky I, Lupski JR, Timmerman V (2003) Mutations in the neurofilament light chain gene (NEFL) cause early onset severe Charcot-Marie-Tooth disease. Brain 126:590-597. doi:10.1093/ brain/awg059

20. Julien JP, Côté F, Collard JF (1995) Mice overexpressing the human neurofilament heavy gene as a model of ALS. Neurobiol Aging 16:487-490 discussion 490-492

21. Kim MS, Chang X, LeBron C, Nagpal JK, Lee J, Huang Y, Yamashita K, Trink B, Ratovitski EA, Sidransky D (2010) Neurofilament Heavy Polypeptide Regulates the Akt- $\beta$-Catenin Pathway in Human Esophageal Squamous Cell Carcinoma. PLoS ONE 5:e9003. doi:10.1371/journal.pone.0009003.

22. Lee JK, Shin JH, Lee JE, Choi E-J (2015) Role of autophagy in the pathogenesis of amyotrophic lateral sclerosis. Biochim Biophys Acta (BBA) Mol Basis Dis 1852:2517-2524. doi:10.1016/j.bbadis.2015.08.005

23. Lee MK, Xu Z, Wong PC, Cleveland DW (1993) Neurofilaments are obligate heteropolymers in vivo. J Cell Biol 122:1337-1350

24. Liu Q, Xie F, Siedlak SL, Nunomura A, Honda K, Moreira PI, Zhua X, Smith MA, Perry G (2004) Neurofilament proteins in neurodegenerative diseases. Cell Mol Life Sci CMLS 61:3057-3075. doi:10.1007/s00018-004-4268-8

25. Mersiyanova IV, Perepelov AV, Polyakov AV, Sitnikov VF, Dadali EL, Oparin RB, Petrin AN, Evgrafov OV (2000) A new variant of Charcot-Marie-Tooth disease type 2 is probably the result of a mutation in the neurofilamentlight gene. Am J Hum Genet 67:37-46. doi:10.1086/302962
26. Moret F, Renaudot C, Bozon M, Castellani V (2007) Semaphorin and neuropilin co-expression in motoneurons sets axon sensitivity to environmental semaphorin sources during motor axon pathfinding. Dev Camb Engl 134:4491-4501. doi:10.1242/dev.011452.

27. Rebelo AP, Abrams AJ, Cottenie E, Horga A, Gonzalez M, Bis DM, SanchezMejias A, Pinto M, Buglo E, Markel K, Prince J, Laura M, Houlden H, Blake J, Woodward C, Sweeney MG, Holton JL, Hanna M, Dallman JE, AuerGrumbach M, Reilly MM, Zuchner S (2016) Cryptic Amyloidogenic elements in the 3' UTRs of Neurofilament genes trigger axonal neuropathy. Am J Hum Genet 98:597-614. doi:10.1016/j.ajhg.2016.02.022

28. Rooke K, Figlewicz DA, Han FY, Rouleau GA (1996) Analysis of the KSP repeat of the neurofilament heavy subunit in familiar amyotrophic lateral sclerosis. Neurology 46:789-790

29. Sandri M (2010) Autophagy in skeletal muscle. FEBS Lett 584:1411-1416. doi: 10.1016/j.febslet.2010.01.056

30. Skvortsova V, Shadrina M, Slominsky P, Levitsky G, Kondratieva E, Zherebtsova A, Levitskaya N, Alekhin A, Serdyuk A, Limborska S (2004) Analysis of heavy neurofilament subunit gene polymorphism in Russian patients with sporadic motor neuron disease (MND). Eur J Hum Genet 12: 241-244. doi:10.1038/sj.ejhg.5201144

31. Song C, Guo J, Liu Y, Tang B (2012) Autophagy and its comprehensive impact on ALS. Int J Neurosci 122:695-703. doi:10.3109/00207454.2012. 714430

32. Taylor JP, Brown RH, Cleveland DW (2016) Decoding ALS: from genes to mechanism. Nature 539:197-206. doi:10.1038/nature20413

33. Uro-Soste E, Fernandez C, Authier F-J, Bassez G, Butori C, Chapon F, Delisle M-B, Dubourg O, Feasson L, Gherardi R, Lacroix C, Laquerriere A, Letournel F, Magy L, Maisonobe T, Marcorelles P, Maurage C-A, Mezin P, Mussini J-M, Penisson-Besnier I, Romero N-B, Streichenberger N, Vallat J-M, Viennet G, Vital A, Voit T, Boucharef W, Figarella-Branger D, Société française de myologie, Association française contre les myopathies $(2010,166)$ Management of muscle and nerve biopsies: expert guidelines from two French professional societies, Société française de myologie et de l'Association française contre les myopathies. Rev Neurol (Paris) 477:-485

\section{Submit your next manuscript to BioMed Central and we will help you at every step:}

- We accept pre-submission inquiries

- Our selector tool helps you to find the most relevant journal

- We provide round the clock customer support

- Convenient online submission

- Thorough peer review

- Inclusion in PubMed and all major indexing services

- Maximum visibility for your research

Submit your manuscript at www.biomedcentral.com/submit
) Biomed Central 